\title{
The loss of PTEN expression and microsatellite stability (MSS) were predictors of unfavorable prognosis in gastric cancer (GC)
}

\author{
J. P. FAN, J. QIAN, Y. J. ZHAO* \\ Department of Gastrointestinal Surgery, People's Hospital of Quzhou, Quzhou, Zhejiang, China \\ ${ }^{*}$ Correspondence: zhaoyujun_zhyj@163.com
}

Received May 21, 2018 / Accepted July 22, 2019

\begin{abstract}
The predictors for the prognosis of gastric cancer (GC) are not clear. We intended to explore the role of PTEN and microsatellite (MS) in GC, showing their potential as prognostic markers. Primary gastric cancer tissues, adjacent normal tissues, and clinicopathological parameters of 187 patients were collected. The expression level of PTEN and MS status were classified by immunohistochemistry (IHC). The relationship among indicators was compared by the chi-square test. The survival curves were delineated by Kaplan-Meier and tested by Log-rank methods. The impact of multiple factors on prognosis was determined by COX proportional hazards model. Significantly, PTEN expression was associated with lymphatic invasion $(\mathrm{p}=0.011)$ and Lauren grade $(\mathrm{p}=0.015)$. MS status was associated with differentiation $(\mathrm{p}=0.006)$ and Lauren grades $(\mathrm{p}=0.035)$. TNM stage was associated with MS status under positive PTEN expression $(\mathrm{p}=0.014)$. Patients with microsatellite stability (MSS) had worse median overall survival (OS) than that with microsatellite instability (MSI) $(\mathrm{p}=0.013)$. Patients with negative PTEN expression had a worse median OS than that with positive PTEN expression $(\mathrm{p}<0.001)$. The tumor subtype of PTEN negative-MSS $(\mathrm{p}<0.001)$ and PTEN negative-MSI $(\mathrm{p}=0.042)$ were strong predictors of poor survival. Negative PTEN expression and MSS might lead to unfavorable prognosis due to their association with clinicopathological parameters of GC. PTEN expression and MS status could be predictors for the prognosis of GC.
\end{abstract}

Key words: PTEN, microsatellite, prognosis, predictor, clinicopathological parameters

Gastric cancer (GC) is one of the most common tumors in the world and the main cause of this disease is Helicobacter pylori infection [1]. At present, the treatment based on surgery is often used in clinical practice, however, the prognosis is still discouraging [1]. According to previous studies, the prognosis of gastric cancer is affected by many factors, among which clinicopathological factors are important indicators for predicting the prognosis of GC patients, including tissue subtypes, lymph node metastasis, TNM staging, and so forth [2]. The understanding of the predictors of prognosis for GC would greatly benefit the intervention of GC.

PTEN is a homolog of tyrosine phosphatase, located in the 10q23 region of human chromosomes and plays a role as a tumor suppressor in many kinds of tumors [3]. Previous researches have reported that PTEN can affect the apoptosis, proliferation, migration, and invasion of tumor cells, as well as inhibit tumor growth by affecting the activation of angiogenic signaling pathways [4]. Recently, Xu et al. revealed that PTEN lipid phosphatase inactivation could induce gastric tumorigenesis, which was linked to the Hippo and phosphatidylinositol 3 kinase/protein kinase B (AKT) PI3K/AKT pathways [5]. Therefore, further studies on the role of PTEN in GC are still valuable.

Microsatellite (MS) is a simple tandem DNA sequence including 1 to 6 nucleotides with a high degree of polymorphism $[6,7]$. MS is distributed more widely in the non-coding regions of the eukaryotic genome than in the coding regions $[6,7]$. The functions of MSs are complex and various $[6,7]$. It is accepted that it plays an important role in the formation and recombination of chromosome structure, which can affect the replication and expression of target genes $[6,7]$. Microsatellite instability (MSI) is a phenomenon when the sequence of MS is inserted or lost bases due to DNA mismatch, which is related to the defects of the mismatch repair (MMR) system [8]. Currently, it is found that MMR-related proteins are composed of at least seven proteins (MLH1, MLH3, MSH2, MSH3, MSH6, PMS1, and PMS2), which specifically bind with each other to form functional heterodimers that can recognize the mismatched base pairs and small nucleotides (1 to 4 base pairs) during the DNA replication $[8,9]$. Besides, MS without a mismatch is defined as microsatellite stability (MSS) [8]. Nowadays, the assessment of MSI is not 
considered to be a marker in the routine evaluation of GC patients due to the existence of a controversial perspective about its prognostic role in GC [10]. Thus, the confirmation of the role of MSI in GC becomes an imperative requirement.

In view of the circumstance described above, we intended to explore the association of PTEN or MS with clinicopathological parameters or prognosis, aiming to exhibit the potential of PTEN and MS as prognostic markers of GC in the treatment of GC.

\section{Patients and methods}

The collection of tissue samples and clinicopathological parameters. The protocol of the present study was approved by the ethics board of the People's Hospital of Quzhou. Patients signed informed consent before the study. Primary gastric cancer tissues, adjacent normal tissues, and clinicopathological characteristics of 187 patients were collected from September $2^{\text {nd }}, 2012$ to September $2^{\text {nd }}, 2013$ in the People's Hospital of Quzhou. Patients ranged in age from 26 to 89 years, with an average age of $57.41 \pm 14.38$. The clinicopathological characteristics of 187 patients are presented in Tables 1, 2, or 3. All patients were confirmed as gastric adenocarcinoma by postoperative pathology, had no family history of tumors and did not receive radiotherapy or chemotherapy before surgery. All patients underwent D2 radical gastrectomy and achieved $\mathrm{R} 0$ resection. The degree of TNM staging and tissue differentiation in gastric cancer was determined according to the criteria established by The Union for International Cancer Control (UICC). Primary gastric cancer tissues and adjacent normal tissues collected from the patients were embedded in optimal cutting temperature compound (OCT, Tissue-Tek O.C.T. Compound, \#4583, SAKURA FINETEK, Torrance, USA) and stored in a $-80^{\circ} \mathrm{C}$ liquid nitrogen immediately. The follow-up was ended at September $2^{\text {nd }}, 2018$, and there were no cases lost to followup. The patient was followed up once a week in the first month after discharge, once every half month in the second month, once every month after 3 months, every 3 months after half a year, and every 6 months after 2 year later. A total of follow-up of 3 to 60 months was made.

Immunohistochemistry (IHC). The tissue was sectioned on a cryostat machine and soaked in distilled water for 5 min. To each section, $50 \mu \mathrm{l}$ of $3 \%$ hydrogen peroxide solution was added and incubated for $10 \mathrm{~min}$ at room temperature (RT) to block the endogenous peroxidase activity. Sections were washed with PBS (P5368-10PAK, Sigma, Burlington, USA) 3 times for $5 \mathrm{~min}$. Sections were incubated in $50 \mu \mathrm{l}$ of Anti-PTEN antibody (ab32199, Abcam, Cambridge, USA, 1:1000), Anti-MLH1 antibody (ab92312, Abcam, Cambridge, USA, 1:1000), Anti-MSH2 antibody (ab227941, Abcam, Cambridge, USA, 1:1000), Anti-MSH6 antibody (ab92471, Abcam, Cambridge, USA, 1:1000), or Anti-PMS2 antibody (ab110638, Abcam, Cambridge, USA, 1:1000) in a humidified box overnight at $4{ }^{\circ} \mathrm{C}$ in a refrigerator. Sections were washed with PBS 3 times for 3-5 min, and rabbit specific HRP/DAB (ABC) Detection IHC kit (ab64261, Abcam, Cambridge, USA) was used to detect the primary antibody. After washing with PBS 3 times for 5 min, sections were observed under a light microscope. When the staining was clear, sections were washed with tap water for 5 min to stop the reaction. Hematoxylin was used for counterstaining for $1 \mathrm{~min}$, and sections were washed with PBS 3 times for 5 min and added $0.5 \%$ ammonia water for returning blue for $30 \mathrm{sec}$. The sections were then subjected to gradient alcohol (75\% alcohol for $2 \mathrm{~min}, 80 \%$ alcohol for $2 \mathrm{~min}$, 95\% absolute alcohol for $2 \mathrm{~min}$ ) for dehydration and xylene solution for transparency for $2 \mathrm{~min}$, and then sealed by neutral balsam. Sections were observed under the microscope using the magnification of $\times 100$ and $\times 200$ and photographed. The presence of brownish-yellow granules in tumor tissues was considered positive staining.

Evaluation of PTEN immunohistochemistry and MS status. According to the proportion of positive staining, the tissue with positive PTEN staining was scored as: 1) 0, no staining; 1 , more than one-third of cells were stained; 2 , one-third to two-thirds of cells were stained; 3, more than two-thirds of cells were stained. 2) According to the intensity of positive staining, the tissue with positive PTEN staining was scored as: 0 , no staining; 1 , light yellow; 2 , brownishyellow; 3, dark brown. The final classifications were determined as a combination of the two scores above: 0 , negative; 2-3, weak positive $(+)$; 4 , moderate positive $(++)$; $5-6$, strong positive $(+++)$.

According to the definition of MSI, tissue samples that exhibited positive staining for all four proteins were considered to be MSS, while samples that were clear-cut negative for at least one of the four proteins were classified as MSI [11]. Thus, the status of MS of patients was classified.

Statistical analysis. Statistical data were analyzed using SPSS13.0 and GraphPad 7.0 software. The relationship among PTEN expression level, MS, and clinicopathological parameters of gastric cancer patients were compared by the chi-square test. The survival curve was delineated by the Kaplan-Meier method and the Log-rank method was used for the significant test. The COX proportional hazards model was used to determine the impact of multiple factors on prognosis. $\alpha=0.05$ was set as a significance level, and $\mathrm{p}<0.05$ was considered to be statistically significant.

\section{Results}

The classification of PTEN expression and association with clinicopathological parameters. In order to classify the expression level of PTEN, we measured the expression of PTEN by IHC. Representative images of positive PTEN staining in cancer or adjacent normal tissues are shown in our results (Figure 1). The expression of PTEN in cancer tissues was lower than that in adjacent tissues (Figure 1). In order to figure out the association of PTEN with clini- 
A

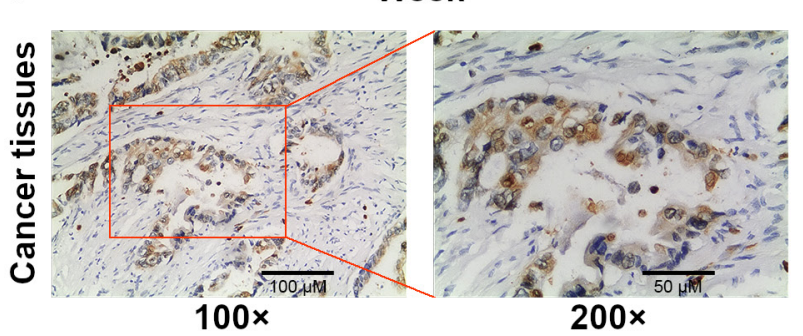

C

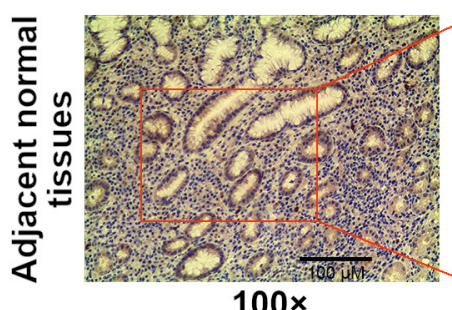

Moderate

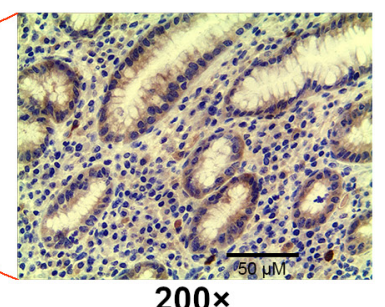

B

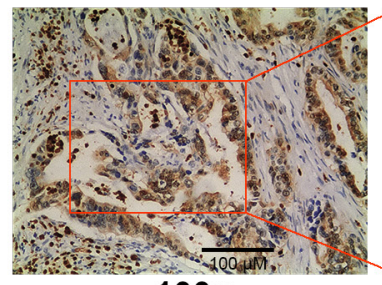

$100 \times$
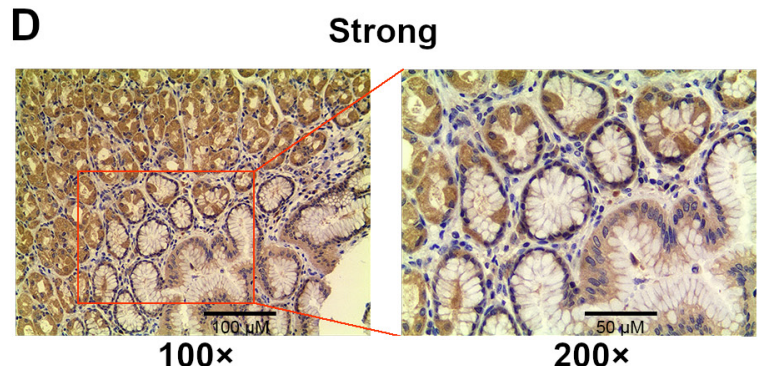

Figure 1. Representative photographs of different expression levels of PTEN by IHC in cancer or adjacent normal tissues. A) The week expression level of PTEN in cancer tissues. B) The moderate expression level of PTEN in cancer tissues. C) The moderate expression level of PTEN in adjacent normal tissues. D) The strong expression level of PTEN in adjacent normal tissues. Magnification of $\times 100$ and $\times 200$ is presented.

copathological parameters, the characteristics of patients we chose were collected. All associations with clinicopathological parameters were given (Table 1 ). The negative PTEN expression was found in $48.66 \%$ of total patients. PTEN expression was only significantly associated with lymphatic invasion $(\mathrm{p}=0.011)$ and Lauren grade $(\mathrm{p}=0.015)$. There was no significance between PTEN expression and age $(\mathrm{p}=0.250)$, gender $(\mathrm{p}=0.951)$, tumor size $(\mathrm{p}=0.223)$, differentiation grade $(\mathrm{p}=0.165)$, TNM stage $(\mathrm{p}=0.084)$, and Ki-67 expression $(\mathrm{p}=0.130)$.

The classification of MSI or MSS and association with clinicopathological parameters. To identify the MSI status of patients, we measured the expression of four major mismatch repair proteins (MMRPs), namely, MLH1, PMS2, MSH2, and MSH6, by IHC. Representative images of the positive staining in cancer tissues are shown (Figure 2). To investigate the association of the status of MS with clinicopathological parameters, all characteristics of patients and their associations with MS were given (Table 2). MSI constituted $35.29 \%$ in total patients while MSS was $64.71 \%$. The status of MS was significantly associated with differentiation grade $(\mathrm{p}=0.006)$ and Lauren grade $(\mathrm{p}=0.035)$. However, there was no significance between the status of MS and age $(p=0.772)$, gender $(p=0.476)$, tumor size $(p=0.470)$, TNM stage $(\mathrm{p}=0.181)$, lymphatic invasion $(\mathrm{p}=0.084)$, Ki-67 expression $(\mathrm{p}=0.657)$.

The association among PTEN expression, status of MS, and clinicopathological parameters. To further explore the relationship among PTEN expression, status of MS, and clinicopathological parameters, the associations among them
Table 1. The classification of PTEN expression and association with clinicopathological parameters.

\begin{tabular}{|c|c|c|c|c|}
\hline \multirow{2}{*}{$\begin{array}{l}\text { Clinicopathological } \\
\text { parameters }\end{array}$} & \multirow[b]{2}{*}{$\mathbf{n}$} & \multicolumn{2}{|c|}{ PTEN expression } & \multirow[b]{2}{*}{ p-value } \\
\hline & & $\begin{array}{c}\text { Negative } \\
(n=91)\end{array}$ & $\begin{array}{c}\text { Positive } \\
(n=96)\end{array}$ & \\
\hline Age & & & & 0.250 \\
\hline$<$ average & 82 & 36 & 46 & \\
\hline$\geq$ average & 105 & 55 & 50 & \\
\hline Gender & & & & 0.951 \\
\hline Female & 60 & 29 & 31 & \\
\hline Male & 127 & 62 & 65 & \\
\hline Tumor size $(\mathrm{cm})$ & & & & 0.223 \\
\hline$<5$ & 101 & 45 & 56 & \\
\hline$\geq 5$ & 86 & 46 & 40 & \\
\hline Differentiation grade & & & & 0.165 \\
\hline High-Moderate & 69 & 29 & 40 & \\
\hline Low & 118 & 62 & 56 & \\
\hline TNM stage & & & & 0.084 \\
\hline $\mathrm{I}+\mathrm{II}$ & 84 & 35 & 49 & \\
\hline III+IV & 103 & 56 & 47 & \\
\hline Lymphatic invasion & & & & 0.011 \\
\hline No & 75 & 28 & 47 & \\
\hline Yes & 112 & 63 & 49 & \\
\hline Lauren grade & & & & 0.015 \\
\hline Intestinal & 115 & 47 & 68 & \\
\hline Diffuse & 23 & 12 & 11 & \\
\hline Mixed & 49 & 32 & 17 & \\
\hline Ki-67 expression & & & & 0.130 \\
\hline Negative & 72 & 30 & 42 & \\
\hline Positive & 115 & 61 & 54 & \\
\hline
\end{tabular}

p-values $<0.05$ are in bold 
Table 2. The classification of MSI or MSS and association with clinicopathological parameters.

\begin{tabular}{|c|c|c|c|c|}
\hline \multirow{2}{*}{$\begin{array}{l}\text { Clinicopathological } \\
\text { parameters }\end{array}$} & \multirow[b]{2}{*}{$\mathbf{n}$} & \multicolumn{2}{|c|}{ MS } & \multirow[b]{2}{*}{ p-value } \\
\hline & & $\begin{array}{c}\text { MSI } \\
(\mathrm{n}=66)\end{array}$ & $\begin{array}{c}\text { MSS } \\
(n=121)\end{array}$ & \\
\hline Age & & & & 0.772 \\
\hline$<$ average & 82 & 28 & 54 & \\
\hline$\geq$ average & 105 & 38 & 67 & \\
\hline Gender & & & & 0.476 \\
\hline Female & 60 & 19 & 41 & \\
\hline Male & 127 & 47 & 80 & \\
\hline Tumor size $(\mathrm{cm})$ & & & & 0.470 \\
\hline$<5$ & 101 & 38 & 63 & \\
\hline$\geq 5$ & 86 & 28 & 58 & \\
\hline Differentiation grade & & & & 0.006 \\
\hline High-Moderate & 69 & 33 & 36 & \\
\hline Low & 118 & 33 & 85 & \\
\hline TNM stage & & & & 0.181 \\
\hline $\mathrm{I}+\mathrm{II}$ & 84 & 34 & 50 & \\
\hline $\mathrm{III}+\mathrm{IV}$ & 103 & 32 & 71 & \\
\hline Lymphatic invasion & & & & 0.084 \\
\hline No & 75 & 32 & 43 & \\
\hline Yes & 112 & 34 & 78 & \\
\hline Lauren grade & & & & 0.035 \\
\hline Intestinal & 115 & 49 & 66 & \\
\hline Diffuse & 23 & 5 & 18 & \\
\hline Mixed & 49 & 12 & 37 & \\
\hline Ki-67 expression & & & & 0.657 \\
\hline Negative & 72 & 24 & 48 & \\
\hline Positive & 115 & 42 & 73 & \\
\hline
\end{tabular}

p-values $<0.05$ are in bold

A

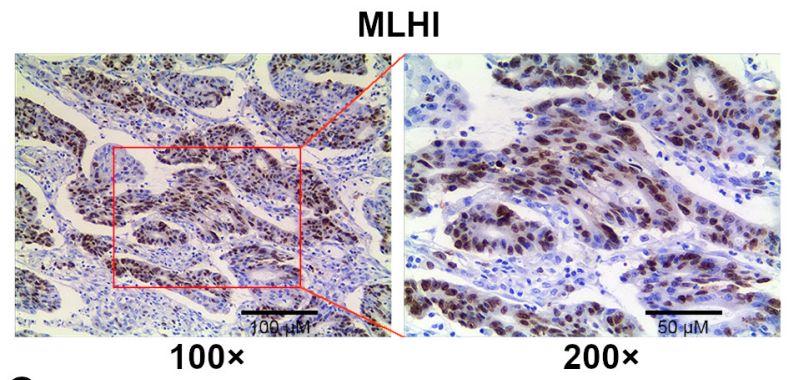

C

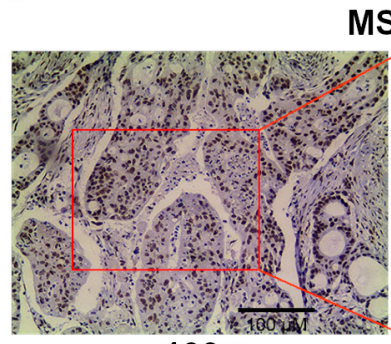

$100 x$
MSH6

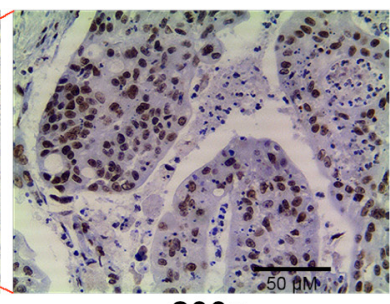

were analyzed and given (Table 3). TNM stage was significantly associated with the status of MS when PTEN expression was positive $(\mathrm{p}=0.014)$. Age $(\mathrm{p}=0.876$ or 0.522$)$, gender $(\mathrm{p}=0.869$ or 0.268$)$, tumor size $(\mathrm{p}=0.759$ or 0.756$)$, differentiation grade $(\mathrm{p}=0.077$ or 0.078$)$, lymphatic invasion $(\mathrm{p}=0.804$ or 0.104 ) Lauren grade ( $\mathrm{p}=0.113$ or 0.375 ), $\mathrm{Ki}-67$ expression ( $p=0.413$ or 0.367$)$ were neither associated with the status of MS under negative PTEN expression nor positive expression.

Survival analysis. In order to investigate the effect of the status of MS and PTEN expression on overall survival of patients with GC, we drew the overall survival curve of patients with MSI or MSS as well as the patients with positive PTEN expression or not (Figures 3A-3B). As shown in the results, patients with MSS had a worse median overall survival than the patients with MSI (Figure 3A, p=0.013). Moreover, patients with negative PTEN expression had a worse median overall survival than the patients with positive PTEN expression (Figure $3 \mathrm{~B}, \mathrm{p}<0.001$ ). To further find out the risk factor affecting the survival rate of patients, patients were divided into four groups as four different tumor subtypes, namely, PTEN positive-MSI, PTEN positive-MSS, PTEN negativeMSI, and PTEN negative-MSS groups, according to the expression of PTEN and the status of MS. The patients with PTEN negative-MSI and PTEN negative-MSS had a worse median overall survival than the patients with PTEN positive-MSI and PTEN positive-MSS (Figure 3C). Multivariate analysis was conducted by COX proportional hazards model (Table 4). The tumor subtype of PTEN negativeMSS (HR 3.011, 95\% CI: 1.691-5.363, p<0.001) and PTEN negative-MSI (HR 2.197, 95\% CI: 1.028-4.696, p=0.042) were strong predictors of poor survival.
B

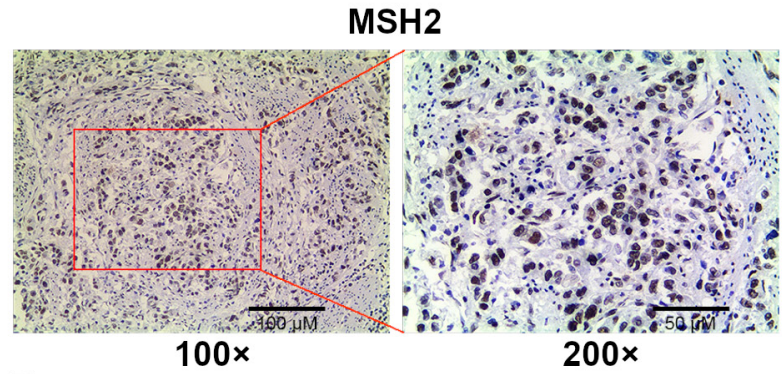

D

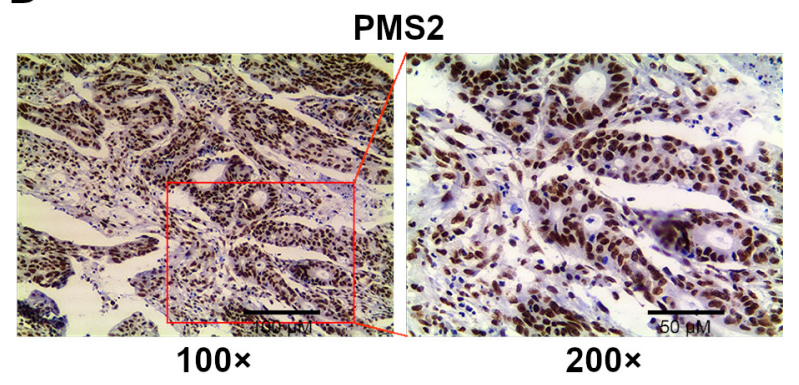

Figure 2. Representative photographs of the expression of MLH1, MSH2, MSH6, and PMS2 in cancer tissues. A) The expression of MLH1. B) The expression of MSH2. C) The expression of MSH6. D) The expression of PMS2. Magnification of $\times 100$ and $\times 200$ is presented. 
A

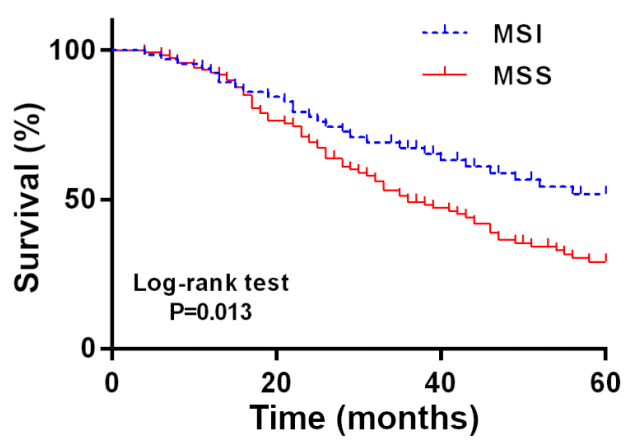

B

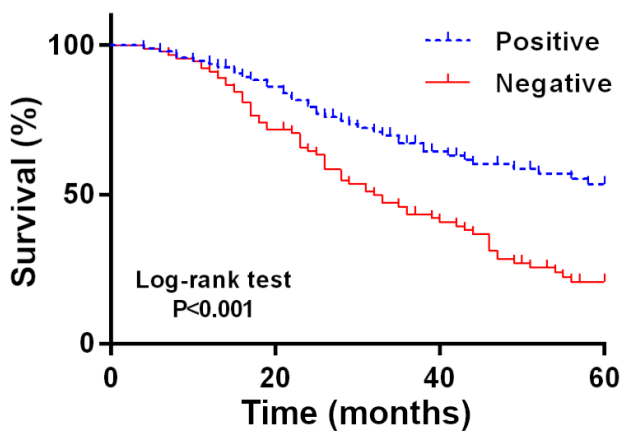

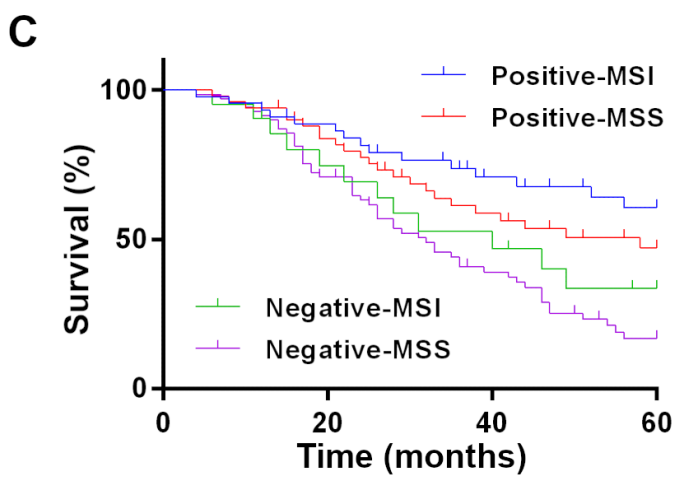

Figure 3. Survival analysis of PTEN and MS. A) The overall survival curves of the status of MS. B) The overall survival curves of PTEN. C) The overall survival curves of the status of MS with or without the expression of PTEN. $p<0.05$ was considered statistically significant

\section{Discussion}

In this study, we measured and classified the expression of PTEN and the status of MS in tissues from patients with GC, and further explored the association of PTEN or MS with clinicopathological parameters or prognosis. Our study provided significant evidence that PTEN and MS might be prognostic markers of GC in the future.

Lauren's histological classification divides GC into intestinal type with the presence of gland formations and a diffuse type with a pattern of poorly cohesive cells, which are related to prognosis, epidemiology, and pathogenic perspective [12]. We found that the PTEN expression was linked to lymphatic invasion and Lauren grade. Zhang et al. revealed that microRNA-21 was significantly associated with lymph node metastasis via regulating PTEN in GC [13]. Li et al. reported that the positive rate of PTEN was related to lymph node metastasis in GC [14]. Furthermore, Zheng et al. demonstrated that intestinal-type gastric cancer always accompanied the strong expression of PTEN [15]. Zheng et al. proved that PTEN expression was linked to Lauren's classification negatively [16]. It indicated that PTEN expression might be closely related to the lymphatic invasion and Lauren grade.
The associations of the status of MS with differentiation grade and Lauren grade were also been seen in the present study. Jahng et al. revealed that the cases with two or more microsatellite instability (MSI) mutations (MSI-H) in the early stage of gastric cancer were associated with histologic differentiation and Lauren grade [17]. Moreover, Arai et al. showed that a much higher amount of cases with MSI were observed with poorly differentiated gastric adenocarcinoma than other subtypes [18]. Polom et al. reported that the status of MS was associated with Lauren histotype [19]. Thus, it suggested that the status of MS was linked to the differentiation and Lauren grade of GC.

Further, we found that there was a significant association of the status of MS with differentiation grade or TNM stage when PTEN expression was negative or positive, respectively. It was proved that the differentiation of gastric cancer cells to intestinal cells could be modulated by PTEN [20]. Investigations also revealed that there was a correlation between reduced nuclear PTEN expression and increasing TNM classification in GC patients [21]. In addition, Choi et al. reported that there was a close relationship between the microsatellite genotype and the TNM stage [22]. Therefore, we speculated that there was a strong linkage between PTEN, the status of MS, and the differentiation grade or TNM stage. 
Table 3. The association among PTEN expression, status of MS and clinicopathological parameters.

\begin{tabular}{|c|c|c|c|c|c|c|c|}
\hline \multirow{2}{*}{ Clinicopathological parameters } & \multirow{2}{*}{$\mathbf{n}$} & \multicolumn{2}{|c|}{ PTEN Negative (91) } & \multirow{2}{*}{ p-value } & \multicolumn{2}{|c|}{ PTEN Positive (96) } & \multirow{2}{*}{$\begin{array}{c}\text { p-value } \\
0.001\end{array}$} \\
\hline & & MSI (n=21) & MSS $(n=70)$ & & MSI $(n=45)$ & MSS $(n=51)$ & \\
\hline Age & & & & 0.876 & & & 0.522 \\
\hline$<$ average & 82 & 8 & 28 & & 20 & 26 & \\
\hline$\geq$ average & 105 & 13 & 42 & & 25 & 25 & \\
\hline Gender & & & & 0.869 & & & 0.268 \\
\hline Female & 60 & 7 & 22 & & 12 & 19 & \\
\hline Male & 127 & 14 & 48 & & 33 & 32 & \\
\hline Tumor size $(\mathrm{cm})$ & & & & 0.759 & & & 0.756 \\
\hline$<5$ & 101 & 11 & 34 & & 27 & 29 & \\
\hline$\geq 5$ & 86 & 10 & 36 & & 18 & 22 & \\
\hline Differentiation grade & & & & 0.077 & & & 0.078 \\
\hline High-Moderate & 69 & 10 & 19 & & 23 & 17 & \\
\hline Low & 118 & 11 & 51 & & 22 & 34 & \\
\hline TNM stage & & & & 0.116 & & & 0.014 \\
\hline $\mathrm{I}+\mathrm{II}$ & 84 & 5 & 30 & & 29 & 20 & \\
\hline III+IV & 103 & 16 & 40 & & 16 & 31 & \\
\hline Lymphatic invasion & & & & 0.804 & & & 0.104 \\
\hline No & 75 & 6 & 22 & & 26 & 21 & \\
\hline Yes & 112 & 15 & 48 & & 19 & 30 & \\
\hline Lauren grade & & & & 0.113 & & & 0.375 \\
\hline Intestinal & 115 & 15 & 32 & & 34 & 34 & \\
\hline Diffuse & 23 & 2 & 10 & & 3 & 8 & \\
\hline Mixed & 49 & 4 & 28 & & 8 & 9 & \\
\hline Ki-67 expression & & & & 0.413 & & & 0.367 \\
\hline Negative & 72 & 9 & 21 & & 15 & 27 & \\
\hline Positive & 115 & 12 & 49 & & 30 & 24 & \\
\hline
\end{tabular}

p-values $<0.05$ are in bold

Table 4. The effect of the status of MS and PTEN expression on overall survival of patients with GC.

\begin{tabular}{lccc}
\hline Tumor subtype & $\mathbf{n}$ & Overall survival HR $(\mathbf{9 5} \% \mathbf{C I})$ & p-value \\
\hline PTEN positive-MSI & 45 & 1 & \\
PTEN positive-MSS & 51 & $1.486(0.775-2.849)$ & 0.233 \\
PTEN negative-MSI & 21 & $2.197(1.028-4.696)$ & $\mathbf{0 . 0 4 2}$ \\
PTEN negative-MSS & 70 & $3.011(1.691-5.363)$ & $<\mathbf{0 . 0 0 1}$ \\
\hline
\end{tabular}

p-values $<0.05$ are in bold

However, the underlying mechanism was still needed to be further investigated.

The patients with MSS exhibited worse prognosis than the ones with MSI as observed by the study of the follow-up data. Zhao et al. found that low-frequency microsatellite instability correlates with a poor prognosis in gastric cancer [23], which supported our findings. One possible reason to explain the outcome was that the status of MS was associated with the differentiation and Lauren grades, which might further affect the prognosis of GC patients. Several investigations had revealed the fact that there were correlations between differentiation and prognosis of GC as well as between Lauren grade and prognosis of GC, which could be the evidence to prove the possibilities. For instance, Chen et al. reported that Lauren's classification was an independent prognostic factor in GC patient undergoing gastrectomy [24], and Adachi et al. found that the overall survival rate of 5 years for patients with well-differentiated GC was higher than that for patients with poorly differentiated GC [25].

The more unfavorable prognosis of patients with negative PTEN expression than the ones with positive PTEN expression was found in our study as well. Chen et al. reported that aberrant expression of PTEN was observed in GC that correlated with poor overall survival [26]. Similarly, we hypothesized that the prognosis of the cases with negative PTEN expression was affected due to the presence of lymphatic invasion and Lauren's classification, which were associated with the expression of PTEN. It could be proved by the fact that lymph node metastasis is a critical marker of prognosis of gastric cancer patients [27]. Moreover, Bu et al. reported that lymphatic vascular invasion is an independent correlated factor for the prognosis of resectable T2 gastric cancer patients [28]. In addition, researches revealed that the patients with intestinal-type gastric carcinomas had a more favorable prognosis [15], while the patients with diffuse- 
subtype tumors had the worst prognosis among all cases in the study of GC [29].

Our study revealed that the cases carrying MSI or MSS with positive PTEN expression had a lower overall survival HR value than the cases with negative PTEN expression, which showed the significance in COX proportional hazards model. It could be explained that the prognosis was influenced by the differentiation grade of GC which was affected by the status of MS under the condition of the loss of PTEN expression. The outcomes also implied the critical role of PTEN expression in the development of GC, affecting the prognosis of patients. Salvesen et al. found that the PTEN methylation was associated significantly with MS unstable phenotype [30]. This research might be circumstantial evidence to explain the outcome in the present study to some extent, however, further investigations are needed to fully understand the relationship between PTEN, MS, and prognosis of GC patients.

In conclusion, negative PTEN expression and MSS might lead to unfavorable prognosis due to their association with clinicopathological parameters of GC patients. The expression of PTEN and the status of MS could be seen as predictors of prognosis for GC patients.

\section{References}

[1] DUTTA S, CRUMLEY AB, FULLARTON GM, HORGAN PG, MCMILLAN DC. Comparison of the prognostic value of tumour and patient related factors in patients undergoing potentially curative resection of gastric cancer. Am J Surg 2012; 204: 294-299. https://doi.org/10.1016/j.amjsurg.2011.10.015

[2] HOTTENROTT C, KATSIOS C. Prognostic significance of host- and tumor-related factors in patients with gastric cancer. World J Surg 2010; 34: 2496-2497; author reply 2498. https://doi.org/10.1007/s00268-010-0554-9

[3] JURIC D, CASTEL P, GRIFFITH M, GRIFFITH OL, WON $\mathrm{HH}$ et al. Convergent loss of PTEN leads to clinical resistance to a PI(3)Ka inhibitor. Nature 2015; 518: 240-244. https://doi.org/10.1038/nature13948

[4] MAO XH, CHEN M, WANG Y, CUI PG, LIU SB et al. MicroRNA-21 regulates the ERK/NF- $\kappa B$ signaling pathway to affect the proliferation, migration, and apoptosis of human melanoma A375 cells by targeting SPRY1, PDCD4, and PTEN. Mol Carcinog 2017; 56: 886-894. https://doi. org/10.1002/mc.22542

[5] XU W, YANG Z, XIE C, ZHU Y, SHU X et al. PTEN lipid phosphatase inactivation links the hippo and PI3K/Akt pathways to induce gastric tumorigenesis. J Exp Clin Cancer Res 2018; 37: 198. https://doi.org/10.1186/s13046-0180795-2

[6] MADESIS P, GANOPOULOS I, TSAFTARIS A. Microsatellites: evolution and contribution. Methods Mol Biol 2013; 1006: 1-13. https://doi.org/10.1007/978-1-62703-389-3_1
[7] CHISTIAKOV DA, HELLEMANS B, VOLCKAERT F. Microsatellites and their genomic distribution, evolution, function and applications: A review with special reference to fish genetics. Aquaculture 2006; 255: 1-29. https://doi. org/10.1016/j.aquaculture.2005.11.031

[8] VELHO S, FERNANDES MS, LEITE M, FIGUEIREDO C, SERUCA R. Causes and consequences of microsatellite instability in gastric carcinogenesis. World J Gastroenterol 2014; 20: 16433-16442. https://doi.org/10.3748/wjg.v20. i44.16433

[9] RICHMAN S. Deficient mismatch repair: Read all about it (Review). Int J Oncol 2015; 47: 1189-1202. https://doi. org/10.3892/ijo.2015.3119

[10] BEGHELLI S, DE MANZONI G, BARBI S, TOMEZZOLI A, ROVIELLO F et al. Microsatellite instability in gastric cancer is associated with better prognosis in only stage II cancers. Surgery 2006; 139: 347-356. https://doi.org/10.1016/j. surg.2005.08.021

[11] SHIA J. Immunohistochemistry versus microsatellite instability testing for screening colorectal cancer patients at risk for hereditary nonpolyposis colorectal cancer syndrome. Part I. The utility of immunohistochemistry. J Mol Diagn 2008; 10: 293-300. https://doi.org/10.2353/jmoldx.2008.0 80031

[12] JIMENEZ FONSECA P, CARMONA-BAYONAS A, HERNANDEZ R, CUSTODIO A, CANO JM et al. Lauren subtypes of advanced gastric cancer influence survival and response to chemotherapy: real-world data from the AGAMENON National Cancer Registry. Br J Cancer 2017; 117: 775-782. https://doi.org/10.1038/bjc.2017.245

[13] ZHANG BG, LI JF, YU BQ, ZHU ZG, LIU BY et al. microRNA-21 promotes tumor proliferation and invasion in gastric cancer by targeting PTEN. Oncol Rep 2012; 27: 1019-1026. https://doi.org/10.3892/or.2012.1645

[14] LI DW, WU Q, PENG ZH, YANG ZR, WANG Y. [Expression and significance of Notch1 and PTEN in gastric cancer]. Ai Zheng 2007; 26: 1183-1187.

[15] ZHENG H, TAKAHASHI H, MURAI Y, CUI Z, NOMOTO K et al. Pathobiological characteristics of intestinal and diffuse-type gastric carcinoma in Japan: an immunostaining study on the tissue microarray. J Clin Pathol 2007; 60: 273277. https://doi.org/10.1136/jcp.2006.038778

[16] ZHENG HC, SUN JM, LI XH, YANG XF, ZHANG YC et al. Role of PTEN and MMP-7 expression in growth, invasion, metastasis and angiogenesis of gastric carcinoma. Pathol Int 2003; 53: 659-666. https://doi.org/10.1046/j.14401827.2003.01542.x

[17] JAHNG J, YOUN YH, KIM KH, YU J, LEE YC et al. Endoscopic and clinicopathologic characteristics of early gastric cancer with high microsatellite instability. World J Gastroenterol 2012; 18: 3571-3577. https://doi.org/10.3748/wjg.v18. i27.3571

[18] ARAI T, SAKURAI U, SAWABE M, HONMA N, AIDA J et al. Frequent microsatellite instability in papillary and solidtype, poorly differentiated adenocarcinomas of the stomach. Gastric Cancer 2013; 16: 505-512. https://doi.org/10.1007/ s10120-012-0226-6 
[19] POLOM K, MARRELLI D, PASCALE V, ROVIELLO G, VOGLINO C et al. High-risk and low-risk gastric cancer areas in Italy and its association with microsatellite instability. J Cancer Res Clin Oncol 2016; 142: 1817-1824. https://doi. org/10.1007/s00432-016-2181-9

[20] BAI Z, ZHANG Z, YE Y, WANG S. Sodium butyrate induces differentiation of gastric cancer cells to intestinal cells via the PTEN/phosphoinositide 3-kinase pathway. Cell Biol Int 2010; 34: 1141-1145. https://doi.org/10.1042/CBI20090481

[21] KIM SJ, LEE HW, BAEK JH, CHO YH, KANG HG et al. Activation of nuclear PTEN by inhibition of Notch signaling induces G2/M cell cycle arrest in gastric cancer. Oncogene 2016; 35: 251-260. https://doi.org/10.1038/onc.2015.80

[22] CHOI SW, CHOI JR, CHUNG YJ, KIM KM, RHYU MG. Prognostic implications of microsatellite genotypes in gastric carcinoma. Int J Cancer 2000; 89: 378-383. https:// doi.org/10.1002/1097-0215(20000720)89:4<378::aidijc10>3.0.co;2-t

[23] ZHAO Y, ZHENG ZC, LUO YH, PIAO HZ, ZHENG GL et al. Low-frequency microsatellite instability in genomic dinucleotide sequences correlates with lymphatic invasion and poor prognosis in gastric cancer. Cell Biochem Biophys 2015; 71: 235-241. https://doi.org/10.1007/s12013-014-0189-9

[24] CHEN YC, FANG WL, WANG RF, LIU CA, YANG MH et al. Clinicopathological Variation of Lauren Classification in Gastric Cancer. Pathol Oncol Res 2016; 22: 197-202. https:// doi.org/10.1007/s12253-015-9996-6
[25] ADACHI Y, YASUDA K, INOMATA M, SATO K, SHIRAISHI N et al. Pathology and prognosis of gastric carcinoma: well versus poorly differentiated type. Cancer 2000; 89: 1418-1424.

[26] CHEN J, LI T, LIU Q, JIAO H, YANG W et al. Clinical and prognostic significance of HIF-1alpha, PTEN, CD44v6, and survivin for gastric cancer: a meta-analysis. PLoS One 2015; 10: e0142287. https://doi.org/10.1371/journal.pone.0142287

[27] DENG H, WU RL, ZHOU HY, HUANG X, CHEN Y et al. Significance of Survivin and PTEN expression in full lymph node-examined gastric cancer. World J Gastroenterol 2006; 12: 1013-1017. https://doi.org/10.3748/wjg.v12.i7.1013

[28] BU Z, ZHENG Z, LI Z, ZHANG L, WU A et al. Lymphatic vascular invasion is an independent correlated factor for lymph node metastasis and the prognosis of resectable T2 gastric cancer patients. Tumour Biol 2013; 34: 1005-1012. https://doi.org/10.1007/s13277-012-0637-3

[29] CRISTESCU R, LEE J, NEBOZHYN M, KIM KM, TING JC et al. Molecular analysis of gastric cancer identifies subtypes associated with distinct clinical outcomes. Nat Med 2015; 21 : 449-456. https://doi.org/10.1038/nm.3850

[30] SALVESEN HB, MACDONALD N, RYAN A, JACOBS IJ, LYNCH ED et al. PTEN methylation is associated with advanced stage and microsatellite instability in endometrial carcinoma. Int J Cancer 2001; 91: 22-26. https:// doi.org/10.1002/1097-0215(20010101)91:1<22::aidijc1002>3.0.co;2-s 